\title{
AXIN2 polymorphism and its association with astrocytoma in a Turkish population
}

\author{
EMINE GULSEN GUNES ${ }^{1}$, ERGUN PINARBASI $^{1}$ and HATICE PINARBASI ${ }^{2}$ \\ Departments of ${ }^{1}$ Medical Biology, and ${ }^{2}$ Medical Biochemistry, \\ Faculty of Medicine, Cumhuriyet University, 58140 Sivas, Turkey
}

Received March 24, 2010; Accepted May 12, 2010

DOI: 10.3892/mmr_00000321

\begin{abstract}
The product of AXIN2, a component of Wnt signalling, plays a role in tumorigenesis and is dysregulated in cancer cells. In order to determine whether the AXIN2 polymorphism is a risk factor for astrocytoma, we analysed eight polymorphic regions of this gene in 100 astrocytoma patients compared to 100 healthy controls in a Turkish population using PCR-RFLP methods. For the Exon1-148 T/C, Exon1-432 C/T, Exon5-1365 G/A, Intron5-1712+19G/T, Exon7-2062 C/T and Intron7-2141+73 G/A SNPs of AXIN2, no significant association between controls and astrocytoma patients was found. For the Exon5-1386 C/T SNP, a statistically significant association between controls and patients was found $(\mathrm{p}<0.05)$. For this astrocytoma, patients with the TT genotype showed an increased risk with an OR of 2.92 (adjusted for age, gender and smoking status) (95\% CI 1.14-7.47) as compared to the controls with the CC genotype. Our results suggest that AXIN2 SNPs may be associated with astrocytoma.
\end{abstract}

\section{Introduction}

Although brain tumors account for a small proportion of all cancers $(1.4 \%)$, most are fatal, and even benign tumors interfere with brain functions essential for daily living (1). Astrocytomas are the most common type of primary human brain neoplasm, accounting for more than $60 \%$ of the total. They form a heterogeneous group of tumors and are classified into grades I, II, III and IV (1). The etiology of brain tumors is poorly characterized, and the relationship between heritable and environmental conditions is unclear. The occurence of brain tumors in hereditary syndromes indicates a genetic susceptibility to brain tumors (1). The role of genetic polymorphisms has been widely investigated in many tumor types, and

Correspondence to: Dr Ergun Pinarbasi, Department of Medical Biology, Faculty of Medicine, Cumhuriyet University, 58140 Sivas, Turkey

E-mail: epinar@cumhuriyet.edu.tr

Key words: AXIN2, polymorphism, astrocytoma, Turkish population the link between tumor suppressor gene polymorphisms and cancer susceptibility has been reported in the literature (2).

The AXIN homologue Conductin, also known as AXIL or AXIN2, functions as a tumor suppressor gene, regulates axis formation during embryonic development and has critical roles in at least three pathways, including the Wnt, stressactivated protein kinase and transforming growth factor $\beta$ (TGF- $\beta$ ) pathways $(3,4)$. AXIN2 functions as a scaffold protein by approximating all the components required for the phosphorilation of $\beta$-catenin, and negatively regulates the Wnt $/ \beta$-catenin pathway $(5,6)$.

In recent years, many studies on the components of the Wnt pathway have revealed not only the importance of this pathway in normal embryonic development, but also in cancer development. Mutations of Wnt pathway components are associated with numerous human cancers, including colon cancer $(7,8)$, melanoma (9), medullablastoma $(10,11)$, hepatocellular carcinoma (12) and ovarian and uterine cancer (13-15). Polymorphisms and mutations of the AXIN2 gene have also been implicated in several types of cancer, but have not been investigated in brain tumors $(1,3)$.

Because of its importance in Wnt signalling and carcinogenesis, we analyzed eight polymorphic regions of the AXIN2 gene in astrocytoma patients in a Turkish population, in order to clarify their association and contribution to this type of tumor.

\section{Materials and methods}

Study population. A total of 200 Turkish individuals were studied, including 100 astrocytoma patients who were admitted to the Neurosurgery Department at Cumhuriyet University Hospital in Sivas (central Anatolia) between the years 2006 and 2008. Only patients with newly diagnosed astrocytomas and no previous radiotherapy or chemotherapy were included in the study. There were no gender, age or grade restrictions. All cases and controls were born in Turkey of native Turkish parents. The diagnosis of astrocytoma was histologically confirmed. Age- and gendermatched controls were recruited mainly from patients (with no previous history of cancer or of radio- or chemotherapy) at the same hospital $(n=100)$. All subjects gave their informed consent for participation in the study and completed a short questionnaire, including questions about occupation, tobacco use, alcohol consumption and history of cancer. The local university ethics committee on human research approved the study. 
Table I. Characteristics of astrocytoma patients and healthy controls.

\begin{tabular}{lcc}
\hline & Patients $(\mathrm{n}=100)(\%)$ & Controls $(\mathrm{n}=100)(\%)$ \\
\hline Gender & $58(58)$ & $46(46)$ \\
Male & $42(42)$ & $54(54)$ \\
Female & $58.66 \pm 8.039$ & $57.01 \pm 7.89$ \\
Age (years \pm SD) & & \\
Smoking habit & $61(61)$ & $70(70)$ \\
Non-smoker & $39(39)$ & $30(30)$ \\
Smoker & & \\
Alcohol consumption & $92(92)$ & $98(98)$ \\
No & $8(8)$ & $2(2)$ \\
Yes & $89(89)$ & 0.089 \\
Family history of cancer & $11(11)$ & $4(96)$ \\
No & & 0.052 \\
Yes & & 0.060 \\
\hline
\end{tabular}

p-values were calculated by the $\chi^{2}$ test.

DNA analysis. Blood samples from patients and controls were collected in citrate-containing tubes. DNA was extracted from blood by a salting out procedure and stored at $-20^{\circ} \mathrm{C}$ until analysis (16).

A total of eight regions, including 5 exons and 3 introns of the AXIN2 gene, were amplified by PCR in 30 cycles using previously reported primers (17). PCR was performed in a reaction volume of $25 \mu \mathrm{l}$, containing $100 \mathrm{ng}$ of genomic DNA, $10 \mathrm{pmol}$ of the appropriate amplification primers, $5 \mathrm{nmol}$ each of four deoxynucleotide triphosphates (Fermentas), 2.5 units of Taq DNA polymerase (Fermentas), $10 \mathrm{mmol} / 1$ Tris- $\mathrm{HCl}$ (pH 8.3 at $25^{\circ} \mathrm{C}$ ), $50 \mathrm{mmol} / 1 \mathrm{KCl}$ and $1.5 \mathrm{mmol} / 1 \mathrm{MgCl}_{2}$. PCR conditions consisted of an initial denaturation at $94^{\circ} \mathrm{C}$ for $5 \mathrm{~min}$, followed by 30 cycles at $94^{\circ} \mathrm{C}$ for $30 \mathrm{sec}, 60^{\circ} \mathrm{C}$ for $30 \mathrm{sec}$ and $72^{\circ} \mathrm{C}$ for $60 \mathrm{sec}$, followed by 1 cycle at $72^{\circ} \mathrm{C}$ for $5 \mathrm{~min}$.

In order to detect the Exon1-148 C/T, Exon1-432 T/C, Intron2-956+16 A/G, Exon5-1365 G/A, Exon5-1386 C/T, Intron5-1712+19G/T, Exon7-2062 C/T and Intron7-2141+73 G/A SNPs of the AXIN2 gene, PCR products were digested with 5 units of Mph1103 I, Esp3 I, Mls I, Mps I, Taq I, Cpo I, $T a q$ I and $B s e R$ I restriction endonucleas enzymes, respectively (Fermentas) in a total reaction volume of $10 \mu \mathrm{l}$ containing $1 \mathrm{X}$ reaction buffer (supplied with the enzyme) for $4 \mathrm{~h}$ at the optimum temperature according to the manufacturer's instructions.

Amplified and digested DNA fragment sizes were as previously reported (17). Following digestion, DNA fragments were seperated on $2.5 \%$ agarose gels.

Statistical analysis. Statistical analysis was performed using the Statistical Package for Social Sciences program (SPSS, version 16). The $\chi^{2}$ test was used to evaluate the association between astrocytoma incidence, tobacco use and AXIN2 genotypes. Statistically significant departures from Hardy-Weinberg equilibrium for the controls were assesed using the $\chi^{2}$ test.

\section{Results}

Characteristics of primary brain tumor patients and healthy controls. A total of 200 individuals (100 patients with astrocytomas and 100 healthy controls) were genotyped for eight regions of the AXIN2 gene. The main charactersitics of the study population are presented in Table I. The mean ages of the patients and controls were 58.66 \pm 8.039 and 57.01 \pm 7.89 years, respectively. The frequency of males and females was 58 and $42 \%$ among the astrocytoma cases and 46 and $54 \%$ among the controls, respectively. Although a family history of cancer was more prevalent in the cases $(11 \%)$ than in the controls (4\%), no statistically significant association was found. The proportion of smokers was significantly higher among patients (39\%) than controls (30\%), and in both groups the majority of smokers were male.

Statistical analysis. Eight regions of the AXIN2 genotype in patients and controls, including allele frequency, genotype distributions, p-values and adjusted OR and 95\% CI values, are presented in Table II. The groups were in Hardy Weinberg equilibrium.

For the Exon1-148 T/C, Exon1-432 C/T, Intron2-956+16 $\mathrm{A} / \mathrm{G}$, Exon5-1365 G/A, Intron5-1712+19G/T, Exon7-2062 $\mathrm{C} / \mathrm{T}$ and Intron7-2141+73 G/A SNPs of the AXIN2 gene, no significant association was found between controls and astrocytoma patients.

For the Exon5-1386 C/T SNP, the frequency of the CC, CT and TT genotypes was 42, 50 and $8 \%$ in the controls, and 36,44 and $20 \%$ in patients, respectively, indicating a statistically significant association between controls and patients. When compared to controls with the CC genotype, patients with the TT genotype showed an increased risk, with an OR of 2.92 (adjusted for age, gender and smoking status) and 95\% CI 1.14-7.47. 
Table II. AXIN2 genotypes in healthy controls and astrocytoma patients.

\begin{tabular}{|c|c|c|c|c|c|}
\hline \multirow[t]{2}{*}{ AXIN2 genotype } & \multirow[t]{2}{*}{ Patients $(\%)$} & \multirow[t]{2}{*}{ Controls (\%) } & \multirow[t]{2}{*}{ p-value } & \multicolumn{2}{|c|}{ OR $(95 \% \mathrm{CI})$} \\
\hline & & & & Crude & Adjusted $^{\mathrm{a}}$ \\
\hline \multicolumn{6}{|l|}{ Exon1-148 C/T } \\
\hline $\mathrm{CC}$ & $39(39)$ & $32(32)$ & 1 & 1 (Reference) & 1 (Reference) \\
\hline $\mathrm{CT}$ & $45(45)$ & $52(52)$ & 0.274 & $0.71(0.38-1.31)$ & $0.68(0.36-1.28)$ \\
\hline TT & $16(16)$ & $16(16)$ & 0.643 & $0.82(0.35-1.89)$ & $0.61(0.25-1.51)$ \\
\hline \multicolumn{6}{|c|}{ Allele frequencies } \\
\hline $\mathrm{C}$ & $123(61.5)$ & $116(58)$ & & & \\
\hline $\mathrm{T}$ & $77(38.5)$ & $84(42)$ & & & \\
\hline \multicolumn{6}{|l|}{ Exon1-432 T/C } \\
\hline TT & $93(93)$ & $95(95)$ & 1 & 1 (Reference) & 1 (Reference) \\
\hline $\mathrm{TC}$ & $7(7)$ & $5(5)$ & 0.352 & $1.80(0.51-6.37)$ & $1.84(0.51-6.57)$ \\
\hline $\mathrm{CC}$ & 0 & 0 & & & \\
\hline \multicolumn{6}{|c|}{ Allele frequencies } \\
\hline $\mathrm{T}$ & $193(96.5)$ & $195(97.5)$ & & & \\
\hline $\mathrm{C}$ & $7(3.5)$ & $5(2.5)$ & & & \\
\hline \multicolumn{6}{|c|}{ Intron2-956+16 A/G } \\
\hline $\mathrm{AA}$ & $70(70)$ & $64(64)$ & 1 & 1 (Reference) & 1 (Reference) \\
\hline $\mathrm{AG}$ & $25(25)$ & $28(28)$ & 0.532 & $0.81(0.43-1.54)$ & $0.81(0.41-1.56)$ \\
\hline GG & $5(5)$ & $8(8)$ & 0.343 & $0.57(0.17-1.83)$ & $0.62(0.19-2.02)$ \\
\hline
\end{tabular}

Allele frequencies
A
G

$165(82.5)$

35 (17.5)

$91(91)$

$9(9)$

GA

Allele frequencies

G

$191(95.5)$

$9(4.5)$

Exon5-1386 C/T

CC
CT
TT
Allele frequencies
C
T

Intron5-1712+19G/T

TT

GT

36 (36)

44 (44)

20 (20)

$116(58)$

84 (42)

$91(91)$

9 (9)

Allele frequencies

$\mathrm{T}$

G

$191(95.5)$

$9(4.5)$

87 (87)

13 (13)

$187(93.5)$

13 (6.5)

$82(82)$

CT

Intron7-2141+73 G/A

GG
156 (78)

44 (22)

88 (88)

12 (12)

1

0.489

1 (Reference)

0.72 (0.29-1.80)

1 (Reference)

0.73 (0.29-1.86)

188 (94)

12 (6)

$42(42)$
$50(50)$
$8(8)$

1 (Reference)

1.02 (0.56-1.87)

$2.91(0.14-7.41)$

1 (Reference)

0.97 (0.52-1.79)

$2.92(1.14-7.47)$

134 (67)

66 (33)

96 (96)

1

1 (Reference)

1 (Reference)

4 (4)

0.152

2.37 (0.70-7.97)

2.00 (0.58-6.93)

196 (98)

4 (2)

Exon7-2062 C/T

$86(86)$

14 (14)

1

1 (Reference)

1 (Reference)

0.836

$0.91(0.40-2.06)$

0.86 (0.37-1.96)

186 (93)

14 (7)

$80(80)$
1 (Reference)

1 (Reference) 
Table II. Continued.

\begin{tabular}{lccccc}
\hline AXIN2 genotype & Patients $(\%)$ & Controls (\%) & p-value & \multicolumn{2}{c}{ OR (95\% CI) } \\
\cline { 4 - 5 } & & & & Crude & Adjusted $^{\mathrm{a}}$ \\
\hline GA & $18(18)$ & $20(20)$ & 0.718 & $0.87(0.43-1.78)$ & $0.80(0.38-1.65)$ \\
Allele frequencies & $182(91)$ & $180(90)$ & & \\
G & $18(9)$ & $20(10)$ & & \\
A & & & \\
\hline
\end{tabular}

p-values were calculated by the $\chi^{2}$ test. ${ }^{a}$ Adjusted for age, gender and smoking status.

\section{Discussion}

Primary brain tumors represent a very heterogenous group of diseases that are poorly understood. Among neurocarcinogenic factors, chemical, physical and genetic factors play important roles. Specific genetic polymorphisms, most commonly those involved in DNA repair, carcinogen metabolism and immune function genes, have been studied in brain tumors, and some promising results have been reported (18-20). The association between carcinogenesis and the AXIN2 polymorpism was recently investigated in a few populations (21-23). The multidomain scaffold protein AXIN2, which is also a tumor suppressor, plays important roles in various biological processes, including Wnt and TGF- $\beta$ signalling (24-27). For the degradation of $\beta$-catenin, it is essential that a component of Wnt signalling be frequently dysregulated in cancer cells $(28,29)$. Thus, the genetic variations that affect the AXIN2 gene may be susceptibility factors for brain tumors. Here, we studied eight polymorphic regions of the AXIN2 gene in astrocytomas, the most common type of primary human brain tumor, in a Turkish population.

In this study, the AXIN2 polymorphism was investigated in 100 astrocytoma patients in a Turkish population, and the results were compared to those from 100 hospital-based controls. Although the frequency of males (58\%), smokers (39\%), family history of cancer (11\%) and alcohol consumption (8\%) was higher among patients than among controls, we found no significant association between the above factors and the studied AXIN2 SNPs.

Mutation studies of the AXIN genes in different types of cancer are well documented (30-33). It has also been reported that AXIN2 SNPs are associated with lung and breast cancers, but not with colorectal and head and neck cancers $(21,23)$.

In our study, we found a significant relationship between the TT genotype of the AXIN2 Exon5-1386 C/T region and astrocytoma risk. The frequency of the TT genotype in patients was higher $(20 \%)$ than in controls $(8 \%)$, which suggests that it is risk factor for astrocytoma development. This finding was confirmed statistically; patients with the TT genotype showed an increased risk of cancer with an adjusted OR of 2.92 (95\% CI 1.14-7.47). Although this region is important for $\beta$-catenin binding on scaffold protein, this SNP has no effect on the protein (3). Insertion and deletion mutations of AXIN2 have been reported in Exon5 (22). It is possible that this SNP together with other mutations contributes to the development or progression of astrocytoma.

We found no association between the incidence of astrocytomas and seven regions of the AXIN2 gene, including Exon1-148 T/C, Exon1-432 C/T, Intron2-956+16 A/G, Exon5-1365 G/A, Intron5-1712+19G/T, Exon7-2062 C/T and Intron7-2141+73 G/A. Although Kanzaki et al and Gunes et al reported a significant association between lung cancer and the AXIN2 Exon1-148 C/T polymorphism causing a Pro50Ser change on the protein in a Japanese population and a Turkish population $(21,23)$, we did not observe any association in our study population, even though the genotype distribution of our control group for this region of AXIN2 was similar to that of the Japanese population.

Another notable finding of the present study was that, although an SNP at the Exon5-1365 G/A region of the AXIN2 gene has been reported to be an $\mathrm{A} / \mathrm{G}$ transition (dbSNP ID: rs9915936), no AA genotype was identified in our control or study groups (34). Therefore, the GG genotype was taken to be the wild-type genotype in our statistical tests.

Gao et al investigated the association of AXIN2 SNPs in Hirschsprung (HSCR) disease, and found that the Exon2rs2240308 and Exon6-rs9913621 polymorphisms contribute to HSCR susceptibility, while Exon5-rs8081536 SNP had no effects on this disease (35).

In another study, the association of genetic variation in genes implicated in the $\beta$-catenin destruction complex with breast cancer risk was reported (22). Five SNPs of AXIN2 and one SNP of APC were found to be associated with an increased risk of breast cancer, suggesting that this pathway plays a role in carcinogenesis. It seems that SNPs of AXIN2 contribute to different biological processes, in particular to tumorigenesis. Our findings support this hypothesis.

In conclusion, this is the first study carried out in a Turkish population investigating the AXIN2 polymorphism and its association with astrocytomas. Our results suggest that the risk of primary brain tumors may be related to the AXIN2 polymorphism, at least in our study population. Further investigations in different populations with large sample numbers are required to support our hypothesis. We believe that the accumulation of knowledge about the genetic changes that make a person susceptible or resistant to brain tumors may eventually result in the prevention of the formation of this disease. 


\section{Acknowledgements}

This study was supported by Grant no. T-299 from Cumhuriyet University CUBAP (Sivas, Turkey). The technical assistance of Ms. Meral Yilmaz is gratefully acknowledged. We also thank Dr Mustafa Gurelik.

\section{References}

1. Bondy ML, El-Zein R and Scheurer ME: Epidemiology of brain tumors. In: M.D. Anderson Cancer Care Series: Tumors of the Brain and Spine. DeMonde F, Gilbert MR, Mahajan A and McCutcheon IE (eds). Springer, New York, pp1-22, 2007.

2. Burim RV, Teixeira SA, Colli BO, et al: ICAM-1 (Lys469Glu) and PECAM-1 (Leu125Val) polymorphisms in diffuse astrocytomas. Clin Exp Med 9: 157-163, 2009.

3. Salahshor S and Woodgett JR: The links between axin and carcinogenesis. J Clin Pathol 58: 225-236, 2005.

4. Smalley MJ and Dale TC: Wnt signalling in mammalian development and cancer. Cancer Metastasis Rev 18: 215-230, 1999.

5. Behrens J, Jerchow BA, Wurtele M, et al: Functional interaction of an axin homolog, conductin, with beta-catenin, APC, and GSK3beta. Science 280: 596-599, 1998.

6. Hart MJ, de los Santos R, Albert IN, Rubinfeld B and Polakis P: Downregulation of beta-catenin by human Axin and its association with the APC tumor suppressor, beta-catenin and GSK3 beta. Curr Biol 8: 573-581, 1998.

7. Morin PJ, Sparks AB, Korinek V, et al: Activation of beta-catenin-Tcf signaling in colon cancer by mutations in betacatenin or APC. Science 275: 1787-1790, 1997.

8. Ilyas M, Tomlinson IP, Novelli MR, Hanby A, Bodmer WF and Talbot IC: Clinico-pathological features and p53 expression in left-sided sporadic colorectal cancers with and without microsatellite instability. J Pathol 179: 370-375, 1996.

9. Rubinfeld B, Robbins P, El-Gamil M, Albert I, Porfiri E and Polakis P: Stabilization of beta-catenin by genetic defects in melanoma cell lines. Science 275: 1790-1792, 1997.

10. Baeza N, Masuoka J, Kleihues P and Ohgaki H: AXIN1 mutations but not deletions in cerebellar medulloblastomas. Oncogene 22: 632-636, 2003.

11. Dahmen RP, Koch A, Denkhaus D, et al: Deletions of AXIN1, a component of the WNT/wingless pathway, in sporadic medulloblastomas. Cancer Res 61: 7039-7043, 2001.

12. Miyoshi Y, Iwao K, Nagasawa Y, et al: Activation of the betacatenin gene in primary hepatocellular carcinomas by somatic alterations involving exon 3. Cancer Res 58: 2524-2527, 1998.

13. Palacios $\mathrm{J}$ and Gamallo $\mathrm{C}$ : Mutations in the beta-catenin gene (CTNNB1) in endometrioid ovarian carcinomas. Cancer Res 58: 1344-1347, 1998.

14. Fukuchi T, Sakamoto M, Tsuda H, Maruyama K, Nozawa S and Hirohashi S: Beta-catenin mutation in carcinoma of the uterine endometrium. Cancer Res 58: 3526-3528, 1998.

15. Polakis P: Wnt signaling and cancer. Genes Dev 14: 1837-1851, 2000.

16. Giner V, Corella D, Chaves FJ, et al: Renin-angiotensin system genetic polymorphisms and essential hypertension in the Spanish population. Med Clin 117: 525-529, 2001

17. Mostowska A, Biedziak B and Jagodzinski PP: Axis inhibition protein 2 (AXIN2) polymorphisms may be a risk factor for selective tooth agenesis. J Hum Genet 51: 262-266, 2006.
18. Bethke L, Webb E, Murray A, et al: Functional polymorphisms in folate metabolism genes influence the risk of meningioma and glioma. Cancer Epidemiol Biomarkers Prev 17: 1195-1202, 2008.

19. Scheurer ME, Amirian E, Cao Y, et al: Polymorphisms in the interleukin-4 receptor gene are associated with better survival in patients with glioblastoma. Clin Cancer Res 14: 6640-6646, 2008.

20. Bondy ML, Scheurer ME, Malmer B, et al: Brain tumor epidemiology: consensus from the Brain Tumor Epidemiology Consortium. Cancer 113 (Suppl 7): 1953-1968, 2008.

21. Kanzaki H, Ouchida M, Hanafusa H, et al: Single nucleotide polymorphism of the AXIN2 gene is preferentially assosiated with human lung cancer risk in a Japanese population. Int J Mol Med 18: 279-284, 2006.

22. Wang X, Goode EL, Fredericksen ZS, et al: Association of genetic variation in genes implicated in the beta-catenin destruction complex with risk of breast cancer. Cancer Epidemiol Biomarkers Prev 17: 2101-2108, 2008.

23. Gunes EG, Pinarbasi E, Pinarbasi H and Silig Y: Strong association between lung cancer and the AXIN2 polymorphism. Mol Med Rep 2: 1029-1035, 2009.

24. Ikeda S, Kishida S, Yamamoto H, Murai H, Koyama S and Kikuchi A: Axin, a negative regulator of the Wnt signaling pathway, forms a complex with GSK-3beta and beta-catenin and promotes GSK-3beta-dependent phosphorylation of beta-catenin. Embo J 17: 1371-1384, 1998.

25. Furuhashi M, Yagi K, Yamamoto H, et al: Axin facilitates Smad3 activation in the transforming growth factor beta signaling pathway. Mol Cell Biol 21: 5132-5141, 2001.

26. Massagué J: TGF-beta signal transduction. Annu Rev Biochem 67: 753-791, 1998.

27. Luo W and Lin SC: Axin: a master scaffold for multiple signaling pathways. Neurosignals 13: 99-113, 2004.

28. Hedgepeth CM, Deardorff MA, Rankin K and Klein PS: Regulation of glycogen synthase kinase 3beta and downstream Wnt signaling by axin. Mol Cell Biol 19: 7147-7157, 1999.

29. Cong F and Varmus H: Nuclear-cytoplasmic shuttling of Axin regulates subcellular localization of beta-catenin. Proc Natl Acad Sci USA 101: 2882-2887, 2004.

30. Clevers H: Axin and hepatocellular carcinomas. Nat Genet 24: 206-208, 2000.

31. Koch A, Hrychyk A, Hartmann W, et al: Mutations of the Wnt antagonist AXIN2 (Conductin) result in TCF-dependent transcription in medulloblastomas. Int J Cancer 121: 284-291, 2007.

32. Liu W, Dong X, Mai M, et al: Mutations in AXIN2 cause colorectal cancer with defective mismatch repair by activating beta-catenin/TCF signalling. Nat Genet 26: 146-147, 2000.

33. Wright $\mathrm{K}$, Wilson $\mathrm{P}$, Morland $\mathrm{S}$, et al: Beta-catenin mutation and expression analysis in ovarian cancer: exon 3 mutations and nuclear translocation in $16 \%$ of endometrioid tumours. Int J Cancer 82: 625-629, 1999.

34. Griffiths-Jones S, Grocock RJ, van Dongen S, Bateman A and Enright AJ: miRBase: microRNA sequences, targets and gene nomenclature. Nucleic Acids Res 34: D140-D144, 2006.

35. Gao H, Zhang J, Wang W, Zhang Z, Huang Y and Zhang S: Association of single nucleotide polymorphisms of Axis inhibitor-2 gene rs224030, rs8081536, rs9913621 with Hirschsprung disease. Zhonghua Yi Xue Yi Chuan Xue Za Zhi 25: 697-700, 2008. 